Katz, A. M., Pearson, C. M., and Kennedy, J. J. (1963). Arthr. and Rheum., 6, 281.

Kelly $\frac{}{1964}$ (1965). Clin. Pharmacol. Ther., 6, 25.

Kelly, M. (1964a). Med. F. Aust., 2, 541.

Lan (1964b). Lancet, 2, 474.

Lansbury, J. (1958). Arthr. and Rheum., 1, 505

Lovgren, O., and Allander, E. (1964). Brit. med. F., 1, 118.

Medical Research Council and Nuffield Foundation (1954). Ibid., 1, 1223

Michotte, L. J., and Wauters, M. (1964). Acta rheum. scand., 10, 273.

Miehlke, K. (1965). Münch. med. W schr., 107, 38.

Norcross, B. M. (1963). Arthr. and Rheum., 6, 290

Percy, J. S., Stephenson, P., and Thompson, M. (1964). Ann. rheum. Dis., 23, 226.

and Thompson, P. (1963). 5th European Congress on Rheumatic Disease.

Robecchi, A., Marrazzi, G., and Viara, M. (1964). Reumatismo, 16, 388.

Robinson, R. G. (1965). Med. F. Aust., 1, 266.

Ropes, M. W., Bennett, G. A., Cobb, S., Jacox, R., and Jessar, R. A. (1957). Ann. rheum. Dis., 16, 118
Rothermich, N. O. (1963). Arthr. and Rheum., 6, 295.

- (1964). Proceedings of 8th Congress of fapan Rheumatism Association (Okayama), p. 159

Rubens-Duval, A., and Villiaumey, J (1964). Rev. Rhum., 31, 204

Smyth, C. J. (1965). Arthr. and Rheum., 8, 921.

- Amoroso, C., and Velayos, E. (1964). Ibid., 7, 345.

and Godfrey, R. (1964). Ibid., 7, 345.

Velayos, E. E., and Amoroso, C. (1963a). Ibid., 6, 299.

- - (1963b). Acta rheum. scand., 9, 306.

Suzman, M. M. (1964). Rhumatologie, 16, 423 .

Thompson, M. (1964). Ibid., 16, 439.

Thompson, M. (1964). Ib1d., 16, 439.

Viara, M., and Marrazzi, G. (1964). Red. F., 1, 80.

Vignau, A I., Correa, E. T., Guasch, J. L., Schuster, A. C., Patri, A. M. Vaisman, S. B., and Mortimer. E. A. (1965). Arthr. and Rheum., 8, 501 .

Wanka, J., Jones, L. I., Wood, P. H. N., and Dixon, A. St. J. (1964) Ann. rheum. Dis., 23, 218

Ward, J. R. (1964). Excerpta Medica International Congress, No. 82 edited by S. Garattini and M. N. G. Dukes, p. 353. Amsterdam.

\title{
Effect of Atrial Systole on Right Ventricular Stroke Output in Complete Heart Block
}

\author{
W. J. GILLESPIE,*† M.D. ; D. G. GREENE,* $\neq$ M.D. ; N. B. KARATZAS,* M.D. \\ G. DE J. LEE,* M.D., F.R.C.P.
}

Brit. med. F., 1967, 1, 75-79

The effect of atrial contraction in augmenting ventricular filling and the proper timing of this event late in ventricular diastole are thought to be important factors for producing optimal stroke output by the heart. Animal studies have repeatedly shown this (Gesell, 1915 ; Wiggers and Katz, 1922 ; Jochim, 1938 ; Linden and Mitchell, 1960 ; Skinner et al., 1963), and in man there has been much renewed interest in the role of atrial function largely because of the development of electrical means for converting cardiac arrhythmias to sinus rhythm (Lown et al., 1962 ; Oram et al., 1963) and for pacing the heart in patients with complete heart block (Sowton, 1964). However, precise evidence in man about the part played by strial contraction is still scanty, chiefly because no direct method is yet available in man for the measurement of beat-by-beat changes in stroke output.

Ideally it would be an advantage to contrive an experimental situation in which the behaviour of the normal human heart was studied under circumstances in which the ventricles contracted at a constant rate while the time interval between atrial and ventricular'systole was varied systematically over the full range of the cardiac cycle. A unique group of healthy individuals enables such a study to be performed in man; and these are subjects with congenital complete heart block. We have therefore made beat-by-beat measurements of right ventricular stroke output in a group of these healthy subjects, and have compared our results with similar measurements made in a second group of patients with complete heart block associated with myocardial disease in order to examine the contribution made by atrial systole to ventricular stroke ouput in each group.

\section{Methods}

Beat-by-beat measurements of right ventricular stroke output were made indirectly from continuous measurement of pulmonary capillary blood flow, the body plethysmograph and nitrous oxide method (Lee and DuBois, 1955) being used. The pulsatile nature of lung capillary blood flow is due to the pulsatile ejection of blood from the right ventricle during each systole, so that beat-by-beat measurements of right ventricular stroke volume may be obtained simply by integrating the volume of each lung capillary blood flow pulsation.

We used a whole-body plethysmograph whose ambient pressure was kept constant by means of a pneumatic servo flowmeter (Stott, 1963). This device automatically detected any change in plethysmograph pressure due to physiological events within the subject's lungs, and instantaneously corrected this change by injecting or extracting air from the chamber at exactly the same rate of gas flow as that occurring in the lungs. The rate of gas transfer by the flowmeter was recorded continuously. The device was linear over its working range of $0-200 \mathrm{ml} . / \mathrm{sec}$. gas flow, with a flat frequency response to $12 \mathrm{c} . / \mathrm{s}$. Pulmonary capillary blood flow was measured throughout the cardiac cycle by continuously recording the rate of $\mathrm{N}_{2} \mathrm{O}$ uptake from the lungs after a single breath of $80 \% \mathrm{~N}_{2} \mathrm{O}$ in oxygen. Details of the procedures undertaken to obtain these measurements have already been published in a paper from this laboratory (Bosman et al., 1964).

In brief the subject lay comfortably inside the body plethysmograph and breathed through a mouthpiece connected to a solenoid-operated valve box opening to the plethysmograph atmosphere on one side and to a 5-litre bag containing $80 \%$ $\mathrm{N}_{2} \mathrm{O}$ in oxygen on the other. After a preliminary period breathing air he was asked to breathe out fully; the solenoid valve was then switched to the $\mathrm{N}_{2} \mathrm{O}$ bag and the subject took a maximal inspiration from the bag. He then breathed out in a slow and relaxed manner for 15 seconds while the plethysmograph-flowmeter curve of $\mathrm{N}_{2} \mathrm{O}$ absorption was made. During this time expired $\mathrm{N}_{2} \mathrm{O}$ concentration at the mouth was measured by an infrared $\mathrm{N}_{2} \mathrm{O}$ meter in closed circuit with the body plethysmograph. The subject's electrocardiogram (lead II) was also recorded for timing purposes. After the $\mathrm{N}, \mathrm{O}$ procedure the subject was switched to breathe from the plethysmograph atmosphere once more. The breathing procedure for the air-

\footnotetext{
* Department of Cardiology, Radcliffe Infirmary ; and the Department of the Regius Professor of Medicine, University of Oxford. † Present address: Department of Medicine, University of Mississippi, Jackson, Miss.

¥ Present address: Department of Medicine, State University of New York at Buffalo, Buffalo General Hospital, Buffalo, N.Y.
} 
control period was identical with that used when $\mathrm{N}_{2} \mathrm{O}$ was inhaled.

Fig. 1 shows a typical record obtained from a healthy subject in sinus rhythm. During air-breathing, shown on the left, small reproducible events took place in the plethysmograph flowmeter record during each cardiac cycle. These resulted from small changes in gas volume which took place in the
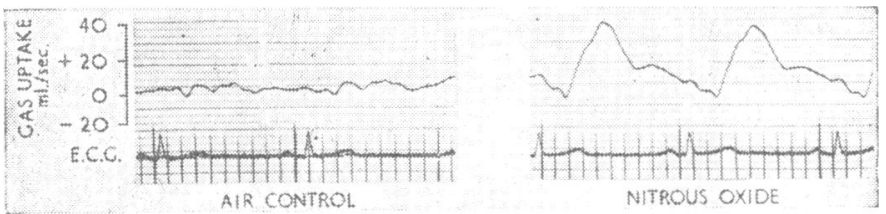

FIG. 1.-Plethysmograph-flowmeter record from a normal subject showing the ratc of change of lung gas volume (gas uptake: $\mathrm{ml}$./ sec.) during air-breathing and after a breath of $80 \% \mathrm{~N}_{2} \mathrm{O}$ in oxygen.

lungs due to mechanical events within the thorax combined with changes in net gas transfer in the lungs due to normal oxygen and $\mathrm{CO}_{2}$ exchange (Bosman and Lee, 1965 ; Bosman et al., 1965). On the right is shown the pulsatile $\mathrm{N}_{2} \mathrm{O}$ uptake record superimposed upon these events.

Right ventricular stroke volume was obtained by integrating the air-control curve planimetrically and subtracting this from the integrated $\mathrm{N}_{2} \mathrm{O}$ curve. This gave the volume of $\mathrm{N}_{2} \mathrm{O}$ absorbed per stroke. The product of this volume divided by the expired $\mathrm{N}_{2} \mathrm{O}$ concentration enabled each right ventricular stroke volume to be calculated, employing the formula:

$$
S V=\frac{\mathrm{VN}_{2} \mathrm{O}}{\mathrm{s}_{\mathrm{N}_{2}} \mathrm{O} \times \mathrm{Fal}_{,} \mathrm{N}_{2} \mathrm{O} \times \mathrm{d}}
$$

where $\mathrm{SV}=$ stroke volume in $\mathrm{ml}$.

$\mathrm{VN}_{2} \mathrm{O}=$ rate of absorption of $\mathrm{N}_{2} \mathrm{O}$ in $\mathrm{ml}$./sec.

$\mathrm{S}_{2} \mathrm{O}=\mathrm{N}_{2} \mathrm{O}$ solubility in whole blood.

$\mathrm{Fal}, \mathrm{N}_{2} \mathrm{O}=$ alveolar concentration of $\mathrm{N}_{2} \mathrm{O}$.

$\mathrm{d}=$ duration of cardiac cycle in seconds.

\section{Results}

Five healthy subjects with congenital complete heart block were studied (Table I, group A). Their average age was 25 years and their heart rates at rest varied from 40 to $45 / \mathrm{min}$. (average $42 / \mathrm{min}$.: R-R' interval $1.40 \mathrm{sec}$.). All subjects were symptomless except one (Case 5), who had been referred to his doctor because he had fainted at the end of a cross-country running competition. A second subject (Case 3) was a keen football player. The two women in the group (Cases 1 and 4) had raised healthy children and had negotiated pregnancy and labour without difficulty. No subject had any past history of illness known to be associated with heart block as a sequel. Some 50 individual measurements of right ventricular stroke volume were obtained from each subject. These were correlated with the P-R interval preceding each measurement of stroke volume. In order to obtain this number of measurements each subject undertook several 15 -second breathing periods with $\mathrm{N}_{2} \mathrm{O}$. A five-minute period breathing air was allowed between each $\mathrm{N}_{2} \mathrm{O}$ period in order to eliminate the $\mathrm{N}_{2} \mathrm{O}$ absorbed during the preceding period.

The measurements of stroke volume were grouped together for each 0.05 -sec. P-R increment, and are shown in Table II. The number of observations made at each $P-R$ increment is shown, as is the standard error of the mean stroke volume for each group. When the preceding $\mathrm{P}-\mathrm{R}$ interval ranged between $0-0.2$ and $0.4-0.9 \mathrm{sec}$. the mean right ventricular stroke volume was $105 \pm 8 \mathrm{ml}$. 'The stroke volume increased by $34 \%$ and averaged $139 \pm 7 \mathrm{ml}$. when the preceding P-R was between 0.2 and 0.4 sec. in duration. Maximal augmentation of stroke volume took place when the preceding $\mathrm{P}-\mathrm{R}$ interval was $0.2-$ $0.25 \mathrm{sec}$. long and amounted to $148 \pm 7 \mathrm{ml}$. ( $40 \%$ increment).
Fig. 2 shows a typical $\mathrm{N}_{2} \mathrm{O}$ uptake record from a healthy subject with congenital complete heart block. The amplitude of each $\mathrm{N}_{2} \mathrm{O}$ uptake is seen to vary in relation to the duration of time between the $\mathrm{P}$ and $\mathrm{R}$ waves of the electrocardiogram immediately preceding the $\mathrm{N}_{2} \mathrm{O}$ uptake curve. Thus the largest stroke volume $(99 \mathrm{ml}$.) is preceded by a P-R interval of 0.16 sec., while the smallest stroke volume $(74 \mathrm{ml}$.) is preceded by a $\mathrm{P}-\mathrm{R}$ interval of $0.36 \mathrm{sec}$. In the latter instance atrial systole occurred early in ventricular diastole during the period of rapid ventricular filling, so that the subsequent right ventricular stroke output was achieved without effective atrial augmentation of ventricular filling.

Table II also shows the results of similar studies obtained from seven patients with symptoms and signs of heart disease associated with complete heart block. Brief clinical details of these patients are given in Table I (group B). The patients' average age was 57 years, and their heart rates at rest ranged from 42 to $61 / \mathrm{min}$. (average $49 / \mathrm{min}$. ; P-R interval $1.23 \mathrm{sec}$.).

TABLE I.-Complete Heart Block

\begin{tabular}{l|l|l|l|l} 
Case \\
No.
\end{tabular} Age Sex $\mid$ B.P. $\left|\begin{array}{c}\text { R-R' } \\
\text { Interval } \\
\text { (sec.) }\end{array}\right| \quad$ Clinical Details

Group A-Healthy Patients

\begin{tabular}{l|l|l|l|l|l}
1 & 22 & $\mathrm{~F}$ & $110 / 70$ & $\mathbf{1} 40$ & Slow pulse found during examination at age 12
\end{tabular}

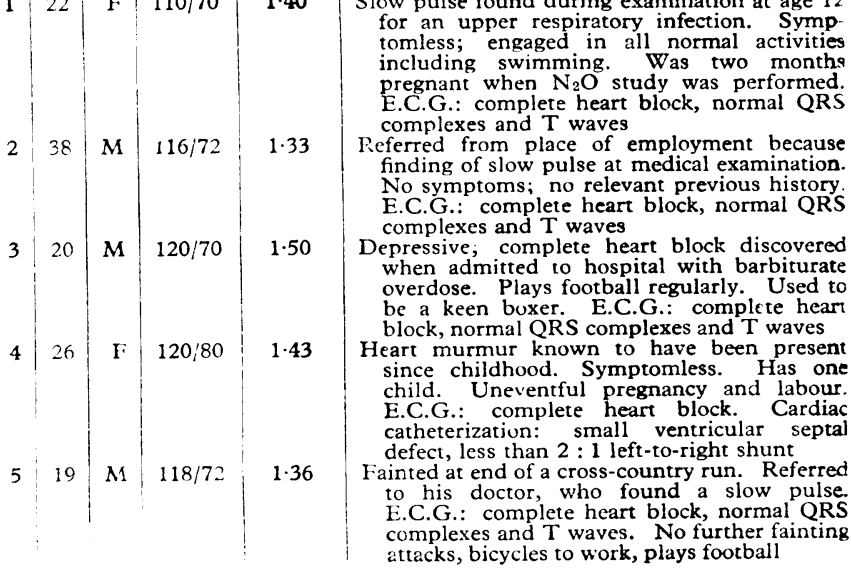

Group B-Patients with Symptoms

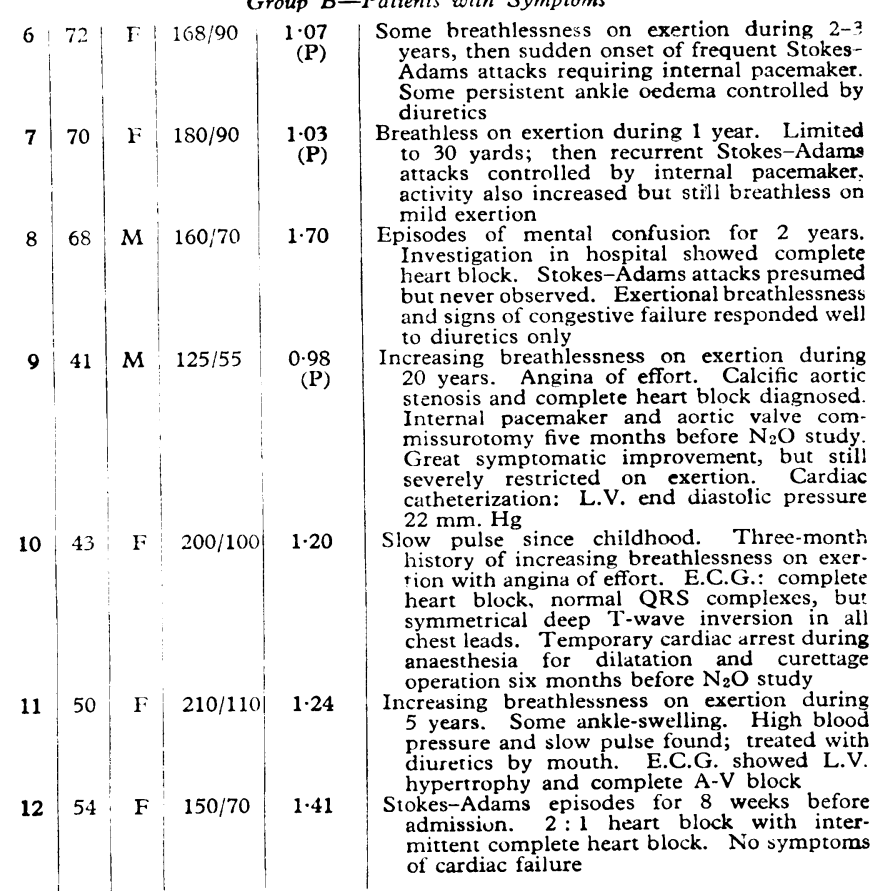
(30 yards; then recurrent Stokes-Adaks. actill breathless on mild exertion

to Angina of effort. Calcinc aortic 作 Great tomy he months berere $\mathrm{N}_{2} \mathrm{O}$ study (a) end diastolic pressure $2 \mathrm{~mm}$. $\mathrm{H}$ press. Some ankle-swelling. High blog Diurerics by mouth. E.C.G. showed L.V. hekes-Adams episodes for 8 weeks before admissiun. $2: 1$ heart block with interof cardiac failure

$(\mathbf{P})=$ Heart rate controlled by internal electrical pacemaker 
One patient (Case 9) had complete heart block associated with aortic stenosis and had undergone successful aortic-valve commissurotomy and was greatly improved, though he still had a limited exercise tolerance when paced with an internal electrode system at 61 beats $/ \mathrm{min}$. Two patients (Cases 6 and 7) were elderly women with acquired complete heart block, initial signs of congestive cardiac failure, and Stokes-Adams attacks relieved by long-term internal electrical pacing but still with greatly decreased exercise tolerance and requiring oral diuretics to control peripheral oedema. Two patients (Cases 10 and 11) were middle-aged women with presumed congenital heart block who had developed gradually increasing symptoms of breathlessness on exertion. One had angina of effort and the other had a

TABLE II.-Right Ventricular Stroke Volume in Relation to Duration of the Preceding $P-R$ Interval

\begin{tabular}{|c|c|c|c|}
\hline $\begin{array}{c}\text { P-R } \\
\text { Interval } \\
\text { (sec.) }\end{array}$ & $\begin{array}{l}\text { Mean } \\
\text { Stroke Volume } \\
\text { (ml.) }\end{array}$ & $\begin{array}{l}\text { S.E. } \\
(\mathrm{ml} .)\end{array}$ & $\mathrm{n}$ \\
\hline \multicolumn{4}{|c|}{ Group A, Five Healthy Subjects with Complete Heart Block } \\
\hline $\begin{array}{l}0-0.05 \\
0.05-0.10 \\
0.10-0.15 \\
0.15-0.20 \\
0.20-0.25 \\
0.25-0.30 \\
0.30-0.35 \\
0.35-0.40 \\
0.40-0.45 \\
0.45-0.50 \\
0.50-0.55 \\
0.55-0.60 \\
0.60-0.65 \\
0.65-0.75 \\
0.75-0.85 \\
0.85-0.95\end{array}$ & $\begin{array}{r}98 \\
93 \\
109 \\
114 \\
148 \\
142 \\
136 \\
128 \\
114 \\
119 \\
99 \\
102 \\
114 \\
98 \\
103 \\
106\end{array}$ & $\begin{array}{r}6 \cdot 9 \\
5 \cdot 1 \\
5 \cdot 0 \\
5 \cdot 8 \\
7 \cdot 3 \\
5 \cdot 5 \\
7 \cdot 4 \\
7 \cdot 1 \\
5 \cdot 8 \\
8 \cdot 3 \\
8 \cdot 6 \\
8 \cdot 0 \\
9 \cdot 8 \\
11 \cdot 2 \\
10 \cdot 2 \\
13 \cdot 4\end{array}$ & $\begin{array}{r}8 \\
11 \\
13 \\
13 \\
16 \\
16 \\
14 \\
10 \\
8 \\
8 \\
8 \\
9 \\
7 \\
5 \\
5 \\
5\end{array}$ \\
\hline \multicolumn{4}{|c|}{$\begin{array}{c}\text { Group B, Seven Patients with Symptoms of Cardiac Decompensation Associated } \\
\text { with Complete Heart Block }\end{array}$} \\
\hline $\begin{array}{r}0-0.10 \\
0.10-0.15 \\
0.15-0.20 \\
0.20-0.25 \\
0.25-0.30 \\
0.30-0.35 \\
0.35-0.40 \\
0.40-0.45 \\
0.45-0.50 \\
0.50-0.60 \\
0.60-0.80\end{array}$ & $\begin{array}{l}70 \\
76 \\
98 \\
86 \\
74 \\
79 \\
58 \\
53 \\
85 \\
82 \\
79\end{array}$ & $\begin{array}{r}6 \cdot 0 \\
10 \cdot 3 \\
6.5 \\
4.9 \\
11 \cdot 0 \\
14 \cdot 7 \\
6 \cdot 0 \\
4 \cdot 8 \\
11 \cdot 8 \\
8 \cdot 7 \\
9 \cdot 7\end{array}$ & $\begin{array}{r}6 \\
4 \\
12 \\
6 \\
4 \\
3 \\
3 \\
3 \\
7 \\
6 \\
5\end{array}$ \\
\hline
\end{tabular}

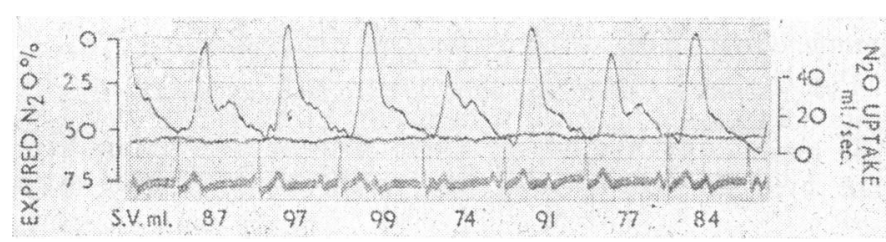

FIG. 2.- $\mathrm{N}_{2} \mathrm{O}$ uptake (ml./sec.); expired $\mathrm{N} O \mathrm{O}$ concentration (\%) E.C.G. ; and stroke volume (S.V.) obtained from a healthy subject with congenital complete heart block. Time intervals $0.2 \mathrm{sec}$.
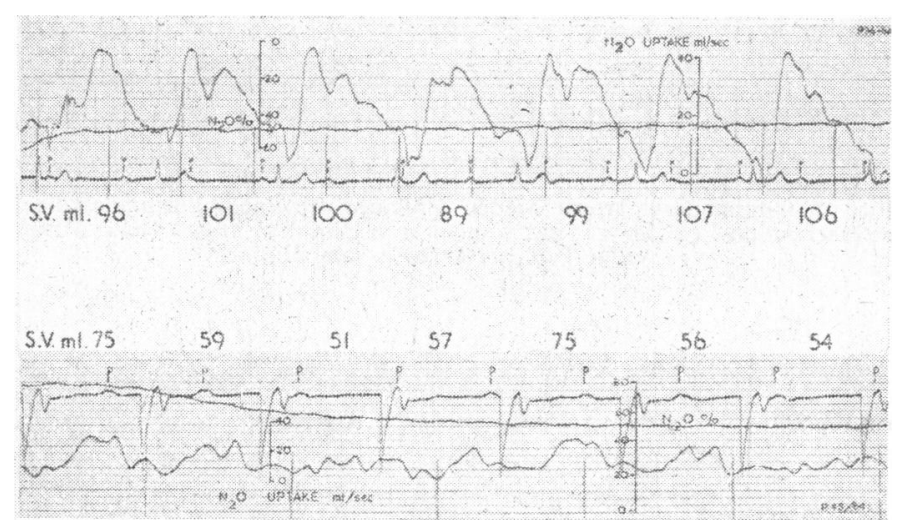

FIG. 3. $-\mathrm{N}_{2} \mathrm{O}$ uptake (ml./sec.) ; expired $\mathrm{N}_{2} \mathrm{O}$ concentration (\%), E.C.G., and calculated stroke output (S.V. ml.) from a patient with complete heart block and angina pectoris (Cंase 10, woman aged 43). FIG. 4.Stroke volume (S.V.); E.C.G. ; expired $\mathrm{N}$. O concentration (\%) and $\mathrm{N}_{2} \mathrm{O}$ uptake (ml./sec.) obtained from a 41 -year-old man (Case 9) with aortic stenosis and complete heart block, paced electrically. raised blood pressure and early signs of congestive cardiac failure, controlled effectively with oral diuretics at the time of study. All patients in this group showed some rise in the jugular venous pressure.

The right ventricular stroke volume was lower than in the healthy group of subjects. When the preceding $\mathrm{P}-\mathrm{R}$ interval was $0-0.15,0.25-0.35$, and $0.45-0.80 \mathrm{sec}$. it amounted to $78 \pm$ $11 \mathrm{ml}$. Only a $13 \%$ augmentation in stroke output took place as a result of atrial systole, and this was found to be optimal when it occurred between 0.15 and $0.20 \mathrm{sec}$. before ventricular systole, when it was associated with a stroke volume of $98 \pm$ 6.5. Moreover, a $28 \%$ decrease in stroke volume appeared to take place when the duration of the preceding $P-R$ interval was between 0.35 and $0.45 \mathrm{sec}$. Under these circumstances right ventricular stroke output from the $\mathrm{N}_{2} \mathrm{O}$ uptake record appeared to fall to $55 \pm 5 \mathrm{ml}$.

Figs. 3 and 4 show $\mathrm{N}_{2} \mathrm{O}$ records obtained from two patients with complete heart block associated with myocardial disease.

Fig. 3 was obtained from a 43-year-old woman (Case 10) who had symptoms of angina of effort. The record shows $\mathrm{N}_{2} \mathrm{O}$ uptake pulses which were more uniform than those obtained from the healthy subject shown in Fig. 2. As a result calculated right ventricular stroke volume varied only between 96 and $107 \mathrm{ml}$. The atrial rate in Fig. 3 was $60 / \mathrm{min}$. and the ventricular rate $50 / \mathrm{min}$. Whenever an atrial contraction took place during ventricular systole it was associated with a transient diminution in the rate of $\mathrm{N}_{2} \mathrm{O}$ uptake, which occurred approximately $0.15 \mathrm{sec}$. after the peak of the associated $P$ wave. This was not an obvious feature in the $\mathrm{N}_{2} \mathrm{O}$ uptake records obtained in our healthy subjects.

Fig. 4 shows the $\mathrm{N}_{2} \mathrm{O}$ uptake record obtained from Case 9 , a man aged 41 with aortic stenosis and complete heart block who was studied six months after aortic valvotomy. His ventricular rate was controlled at $61 / \mathrm{min}$. by means of an internal pacemaker. Left heart catheterization some weeks before the $\mathrm{N}_{2} \mathrm{O}$ study had revealed an end diastolic left ventricular pressure of $20 \mathrm{~mm}$. Hg. When atrial contraction occurred late in each preceding ventricular diastolic period the $\mathrm{N}_{2} \mathrm{O}$ uptake record was pulsatile, but the pulse was delayed and slow-rising compared with normal. When an atrial systole also coincided with ventricular systole $\mathrm{N}_{2} \mathrm{O}$ uptake became uniform and pulsatility was abolished.

\section{Discussion}

Before discussing our studies on the contribution made by atrial systole to right ventricular stroke output it is necessary to examine the validity of the assumption that the integrated volume of each pulmonary capillary blood flow pulsation truly corresponds to the right ventricular stroke output.

Studies in the dog and in man which have been undertaken in this laboratory (Bosman et al., 1964) have shown that the $\mathrm{N}_{2} \mathrm{O}$-plethysmograph-flowmeter method correlates closely with the direct Fick method for measuring cardiac output. The assumption that $\mathrm{N}_{2} \mathrm{O}$ uptake is a true measure of instantaneous pulmonary capillary blood flow also appears to be fully justified (Bosman et al., 1965). Blood flow through the lung capillaries is largely dependent upon the dynamic relations which exist between the intra-alveolar pressure tending to close the lung capillaries and the distending pressures which act as a gradient of propulsion between the pulmonary artery and venous systems as a result of cardiac action coupled with hydrostatic factors within the lungs imposed by gravity (West, 1966). These physical relations govern the regional distribution of blood flow within the lungs, and the summation of these regional flow components results in the pattern of total capillary blood flow throughout the cardiac cycle, which is measured by $\mathrm{N}_{2} \mathrm{O}$ uptake. We have shown that the $\mathrm{N}_{2} \mathrm{O}$ upiake record closely resembles the pulmonary-artery/left-atrial pressure difference (Bosman et al., 1962). 
In normal circumstances the $\mathrm{N}_{2} \mathrm{O}$ uptake curve virtually resembles the pulmonary artery pressure curve alone. This is because the normal left atrial pressure fluctuates only a few $\mathrm{mm} . \mathrm{Hg}$ pressure about its mean value, and at this pressure level the compliant pulmonary veins seem to damp out such pulsations from retrograde transmission to the capillaries. It is for this reason that indirect measurement of left atrial pressure events with the transcapillary method during cardiac catheterization may fail to correlate with simultaneous measurements of pressure made direct from the left atrium itself at normal pressures (Allison and Linden, 1953). The explanation for this may be found in recent studies by Caro (1966), who has shown that the pulmonary venous system has an extremely nonlinear compliance with considerable distensibility at low intravascular pressures but that it rapidly becomes indistensible as the venous pressure is raised. Thus quite moderate elevation of the left atrial pressure will be accompanied by loss of pulmonary venous compliance. Under such circumstances pressure fluctuations taking place in the left atrium would be expected to be transmitted retrograde to the lung capillaries through the now noncompliant venous system, with little attenuation of wave form. The compliance of the pulmonary arterial system, on the other hand, is much more linear (Caro, 1966), so that attenuation of its pressure pulse will tend to be more uniform over a much wider range of pressure.

These considerations impose clear implications upon the assumption that a close correlation will exist between the integrated volume of each pulmonary capillary blood flow pulse and the right ventricular stroke output associated with it. The assumption will be true only when the left atrial pressure is normal. The pulmonary capillary blood flow pulsation will then correlate closely with the dynamic characteristics of the pulmonary artery pressure minus the mean left atrial pressure; for when the left atrial pressure is low the output impedance to blood flow leaving the lung capillaries will be constant, and variations in the instantaneous capillary blood flow rate throughout the cardiac cycle will be entirely dependent upon changes in the pulmonary arterial pressure imposed as a result of right ventricular ejection.

However, when the left atrial pressure is raised fluctuations in its pressure will be transmitted to the capillaries via the now relatively indistensible pulmonary veins in addition to pressure events reaching the capillaries via the arterial system, with the result that variations in the instantaneous pulmonary capillary blood flow rate measured by $\mathrm{N}_{2} \mathrm{O}$ uptake will now be dependent upon events occurring both in the left atrium and in the right ventricle. Under these circumstances the integrated volume of the pulmonary capillary blood flow pulse will not correlate so well with right ventricular stroke output. However, the profile of the instantaneous $\mathrm{N}_{2} \mathrm{O}$ uptake record will now give useful indirect information about pressure changes taking place in the pulmonary veins and left atrium (Bosman et al., 1962). Studies which we are now making of $\mathrm{N}_{2} \mathrm{O}$ uptake with simultaneous direct measurement of the pulmonary-artery/left-atrial pressure difference during diagnostic cardiac catheterization of patients with mitral valve disease confirm this, and will be published in due course.

We did not feel justified in performing cardiac catheterization to measure the intracardiac pressures in our healthy subjects, but clinical examination revealed no rise in their jugular venous pressures at rest, and our $\mathrm{N}_{2} \mathrm{O}$ uptake studies showed a normally pulsatile $\mathrm{N}_{2} \mathrm{O}$ uptake profile, indicating that the left atrial pressure was within normal limits and was not episodically changing the outflow impedance from the lung capillary system. We therefore felt confident that measurement of the integrated volume of each pulmonary capillary blood flow pulse in our healthy subjects with complete heart block gave a true measure of each right ventricular stroke output associated with it.

Table II (group A) shows that our healthy subjects with congenital complete heart block had a resting right ventricular stroke volume of $105 \mathrm{ml}$. when lying recumbent. Atrial systole had little effect in altering right ventricular filling unless it took place late in ventricular diastole, when it produced up to $40 \%$ augmentation in right ventricular stroke output if timed to take place $0.2-0.25 \mathrm{sec}$. before the onset of ventricular systole, when the heart rate averaged $42 / \mathrm{min}$. We believe that this group of healthy subjects with congenital complete heart block act as a true model for the study of the behaviour of the normal heart, and that we have thus been able to examine the effect on stroke output by the normal heart when the time interval between atrial and ventricular contraction is varied in a systematic fashion.

Our group of patients with complete heart block and myocardial disease acted as a similar model to investigate whether atrioventricular synergy was also important for achieving optimal output by the failing heart. This has special relevance today, when electrical conversion of atrial fibrillation to sinus rhythm is often undertaken in the hope of improving cardiac function in addition to reducing the risk of embolization so commonly associated with atrial fibrillation.

Our results in seven patients with myocardial disease indicated that atrioventricular synergy was less effective in augmenting right ventricular stroke output than in the healthy group (Table II, group B). An unexpected finding also emerged from these results, for an apparent decrease in right ventricular stroke volume was observed in cardiac cycles where the $P-R$ interval was between 0.35 and $0.45 \mathrm{sec}$. In all these cycles an additional $\mathrm{P}$ wave was buried within the relevant $\mathrm{Q}-\mathrm{T}$ interval. This suggested that simultaneous atrial and ventricular systole was responsible for the finding.

We have already mentioned that pressure pulsations originating in the left atrium will affect pulmonary capillary blood flow when the mean left atrial pressure is elevated because of the loss of pulmonary venous compliance with which it is associated. When atrial contraction takes place against a closed mitral valve during ventricular systole it will result in the production of a venous cannon wave. At low left atrial pressures this wave will become attenuated by the pulmonary venous system. But at higher left atrial pressures the wave will be transmitted to the capillaries, when it will impose a momentary increase in impedance to capillary blood flow. Wedge pulmonary artery pressure tracings obtained in two patients with complete heart block demonstrate these differences.

Fig. 5 shows the wedge pulmonary artery pressure record from a 54-year-old woman with acquired complete heart block. The mean wedge pulmonary artery pressure was $8 \mathrm{~mm}$. $\mathrm{Hg}$. The pressure record shows that when atrioventricular syn-

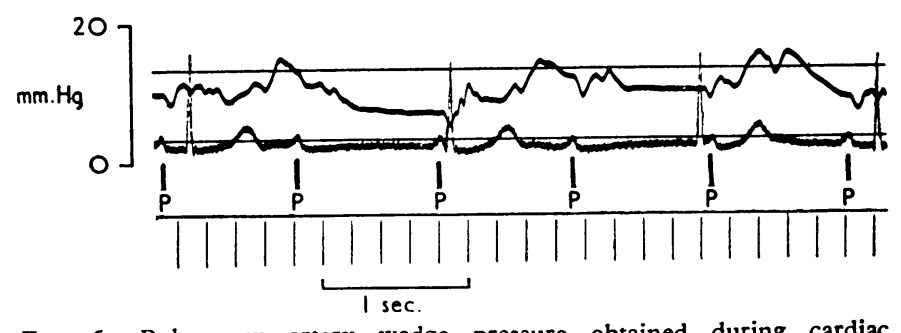

FIG. 5.-Pulmonary artery wedge pressure obtained during cardiac catheterization in a 54-year-old woman with complete heart block. Mean wedge P.A. pressure $=8 \mathrm{~mm}$. $\mathrm{Hg}$.

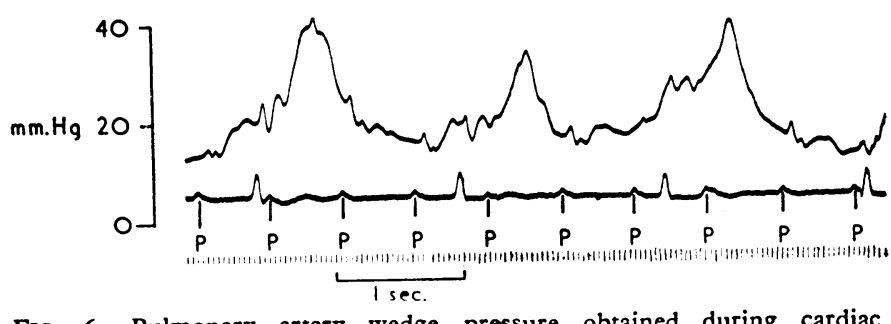

Fig. 6.-Pulmonary artery wedge pressure obtained during cardiac catheterization in a 41 -year-old man (Case 9) with complete heart
and aortic stenosis. Mean wedge P.A. pressure $=22 \mathrm{~mm}$. $\mathrm{Hg}$. 
chrony took place it was not associated with any augmentation in the size of the "a" wave recorded at other times. Fig. 6, on the other hand, was obtained from the patient (Case 9) who had complete heart block associated with aortic stenosis. His left ventricular and diastolic pressure was $20 \mathrm{~mm}$. $\mathrm{Hg}$, and his wedge pulmonary artery pressure $22 \mathrm{~mm}$. $\mathrm{Hg}$. Large cannon waves as high as $40 \mathrm{~mm}$. $\mathrm{Hg}$ were recorded on the wedge pulmonary artery pressure record whenever atrioventricular synchrony took place. Fig. 4 shows the $\mathrm{N}_{2} \mathrm{O}$ uptake record obtained from the same patient (Case 9). The loss of pulsatility in the $\mathrm{N}_{2} \mathrm{O}$ record during cycles when atrial and ventricular systole coincide is seen as a result of the temporary increase in venous impedance imposed by the cannon wave. Thus the decrease in lung capillary blood flow which was found when the P-R interval was 0.35-0.45 sec. (Table II, group B) was due largely to this phenomenon and does not necessarily imply an associated decrease in right ventricular stroke output.

A comparison of the diffserence between our healthy subjects and our patients with myocardial disease in their response to optimal timing of atrial systole on stroke output explains some of the contradictory findings of previous workers when studying the effects of conversion of atrial fibrillation to sinus rhythm. Both Henderson et al. (1906) and Lewis (1912) have concluded from animal experiments that atrial contraction had little effect in augmenting ventricular filling, though Wiggers and Katz (1922) later showed that atrial systole could contribute between 18 and $60 \%$ of the total volume of blood entering the ventricles during diastole.

The results obtained from such experiments were very dependent upon the physiological state of the animal preparation at the time of measurement, and this could well explain such divergent findings. This is all the more relevant when considering studies in man. Thus Kory and Meneely (1951) showed a $43 \%$ increase in cardiac output when patients with lone atrial fibrillation were converted to sinus rhythm with quinidine; while similar studies of cardiac output in patients with atrial fibrillation associated with a variety of conditions, including a high proportion of patients with valvular disease, showed much less augmentation of cardiac output after conversion (Oram et al., 1963).

Our studies also suggest that the augmentation of stroke volume that takes place when atrial systole is correctly timed to boost ventricular filling in late diastole can achieve this response only when the ventricular myocardium is healthy. This has therapeutic application when internal electrical pacing methods are under consideration for the long-term treatment of patients with complete heart block. The bulk of such patients have associated myocardial disease, and are exemplified by our group B patients, who had little augmentation in stroke volume as a result of atrioventricular synergy. Thus the added benefit of pacing such patients with electrical stimuli triggered from the atria rather than using present conventional isolated ventricular pacing methods would not scem likely to offer much increased benefit. Indeed, the added risk of instrumental failure because of the greater complexity of atrial-triggered equipment, coupled with its greater cost, may well detract from its advantages. Final conclusions will depend on exercise sturdies in patients with complete heart block who have been fitted with atrial-triggered equipment, for this will make possible an increased cardiac output in response to exercise by triggering an increased ventricular rate.

\section{Summary}

Correct synchrony between atrial and ventricular contraction has been thought important for the achievement of optimal stroke output by the heart, but evidence for this in man has been contradictory.

Right ventricular stroke volume was therefore measured indirectly with the N.O-plethysmograph method for recording instantaneous pulmonary capillary blood flow in subjects whose ventricular rates were constant but in whom the P-R interval varied widely.

Two model groups were studied: group A, five healthy subjects with congenital complete heart block; and group B. seven patients with complete heart block associated with myocardial disease.

In group $\mathrm{A}$ the mean right ventricular stroke volume was $105 \mathrm{ml}$. when the P-R interval was between $0-0.2 \mathrm{sec}$. and $0.4-0.9 \mathrm{sec}$. The stroke volume increased by $40 \%$ when the $\mathrm{P}-\mathrm{R}$ interval was $0.2-0.25 \mathrm{sec}$.

In group $B$ the mean right ventricular stroke volume was smaller (78 ml.) and atrioventricular synergy produced only $13 \%$ augmentation.

In group $\mathrm{B}$ a $28^{\circ}$, decrease in lung capillary blood flow occurred when the previous $\mathrm{P}-\mathrm{R}$ interval was between 0.35 and 0.45 sec., because the subsequent atrial contraction invariably coincided with ventricular systole. The left atrial cannon wave so produced lowered the pulmonary-artery/left-atrial pressure gradient, consequently decreasing lung blood flow, at this time. This effect was undetectable in the healthy subjects.

It is concluded that atrial systole has a powerful augmentative effect upon stroke output in the normal heart, while its effect is less valuable when the myocardium is diseased.

We are grateful to Dr. Aubrey Leatham and Dr. Geoffrey Wade for their interest and for referring patients to us. The body plethysmograph was supplied by Vickers Research Ltd. The investigation was supported in part by a grant from the British Heart Foundation and in part by the U.S.A.F. School of Aerospace Medicine under Contract AF 61(052)-746 through the European Office of Aerospace Research (O.A.R.), United States Air Force.

\section{REFERENCES}

Allison, P. R., and Linden, R. J. (1953). Circulation, 7, 669.

Bosman, R., Honour, A. J., Lee, G. de J., Marshall, R., and Stott, F. D (1962). Memorias del IV Congresso Mundial de Cardiologia, Mexico, Tom. IA, p. 244.

and Lee, G. de I. (1965). Ibid., 28, 311 .

-

Caro, C. G. (editor) (1966). Advences in Respiratory Physiology, Chap 7 , p. 255 . London.

Gesell, R. (1915). Amer. 7. Physiol., 38, 404

Genderson, Y., Scarborough, M. M. R., and Chillingworth, F. P. (1905) Ibid., 16, 325 .

Jcchim, K. (1938). Ibid., 122, 639.

Kory, R. C., and Meneely, G. R. (1951). f. clin. Invest., 30, 653.

Lee, G. de J., and DuBois, A. B. (1955). Ibid., 34, 1380.

Lewis, T. (1912). f. exp. Med., 16, 395.

Linden, R. J., and Mitchell, J. H. (1960). Circulat. Res., 8, 1092.

Lown, B., Amarasingham, R., and Neuman, J. (1962). 'F. Amer. med Ass., 182, 548.

Oram, S., Davies, J. P. H., Weinbren, I., Taggart, P., and Kitchen, L. D. (1963). Lancet, 2, 159.

Skinner, N. S., iun., Mitchell, J. H., Wallace. A. G., and Sarnoff, S. ] (1963). Amer. F. Physiol., 205, 499.

Sowton, E. (1964). Brit. Heart f., 26, 737.

Sowton, E. (1964). Brit. Heart f., 26, 737.

West, J. B. (1966). Ventilation Blood Plow and Gas Exchange. Oxford Wiggers, C. J., and Katz, L. N. (1922). Amer. \%. Physiol., 58, 439. 